\title{
The Effectiveness of Emotion-focused Cognitive Therapy in Decreasing Depression due to Marital Relationship Problems
}

\author{
Seyedeh Fatemeh Hashemi, Seyed Ali Kimiaei* \\ College of Education and Psychology, Ferdowsi University of Mashhad, Iran
}

Copyright $(2017$ by authors, all rights reserved. Authors agree that this article remains permanently open access under the terms of the Creative Commons Attribution License 4.0 International License

\begin{abstract}
Marital distress and marital relationship problems are effective in generation and acceleration of depression. Depression is a significant contributor to the global burden of disease and affects people in all communities across the world. This study aims to determine the effectiveness of emotion-focused cognitive therapy in decreasing depression caused due to marital relationship problems. The design of this study was semi-experimental with pre-test, post-test and control group. The research population consisted of all couples referred to the Ferdowsi University of Mashhad Clinic of Psychology. 10 couples with marital problems were selected by convenience sampling, and randomly assigned to an experimental group and a control group. The experimental group received emotion-focused cognitive therapy while the control group received no treatment. The research measurement instruments consisted of BDI-II and CPQ. ANCOVA models were used to test the study hypothesis. The results showed that EFCT had been effective in decreasing depression due to marital relationship problems $(\mathrm{P}<0.001)$. The results of our study not only demonstrated that the importance of cognition and emotion in marital relationship but also product useful information about effectiveness of EFCT on depression caused due to marital relationship problems for researchers, counselors and psychotherapists.
\end{abstract}

Keywords Emotion-focused Cognitive Therapy, Depression, Marital Relationship Problems

\section{Introduction}

Couples in their marital life communicate with each other through many different ways. Those communications ways, which are often taken in a family, called communication patterns [1].Most couples with marital conflict do have problems in communication with each other. These couples are mostly engaged in ineffective communication patterns [2]. Gottman and Notarius [3] believed that one of the factors influencing marital satisfaction is communication patterns. As the couples get better at sending clear messages and listening better, it will be time to address those underlying emotional issues that influence conflict management and resolution [4]. The quality of couple's communication has been found to be one of the best predictors of relationship satisfaction [5].

Whisman [6] conducted a meta-analysis on 26 studies, where both depressive symptoms and marital satisfaction were assessed and found that "... the weighted mean effect size (correlation) between depressive symptoms and marital satisfaction [7]. Many studies have shown the relationship between depression and marital problems and have identified a significant relationship between marital distress and depression symptoms in married people $[8 ; 9 ; 10]$. Studies of Baech et al [11] suggests marital distress and certain type of marriage events are effective in the generation and acceleration of depression. Garman [12] believes that the importance of marital conflicts and the problems in the couple's relationship and the role of social context, as the great variables in the etiology of depression, are undeniable. Depression is a significant contributor to the global burden of disease and affects people in all communities across the world. Today, depression is estimated to affect as many as 350 million people [13].

CBT is one of the most effective treatments for depression [14]. Butler et al [15] in their review of 16 recent meta-analysis sought to answer a multifaceted question: how effective is CBT, for which disorders, and compared to what, and how lasting are these effects? Collectively, the findings detailed in this review suggest that CT is highly effective for adult unipolar depression. Cognitive science and cognitive behavioral therapies can absolutely be congratulated for the benefits they have brought to academics, to clinicians and to clients. But unfortunately something has been left out in these great strides forward-and that is emotion [16]. 
Emotion and cognition are intimately and inextricably tied together [17]. Both emotional and cognitive symptoms are present in depression [18]. Emotion-focused cognitive therapy is a new form of CBT with emotion regulation components. Power and his colleague Tim Dalgleish have developed the SPAARS (schematic, propositional, analogical and associative representational systems) model over the past decade or so. SPAARS is the integrated cognitive model of emotion. The various types of representation and processing systems are as follows: 1 . The analogical system: this system refers to a collection of primarily sensory-specific systems that include vision, hearing, taste, smell, touch and kinesthetic systems 2 . The associative system: this system typically operates automatically and outside awareness; it includes the innate-based starting points for the emotion and other systems that develop over the time according to associative learning mechanisms; skills-based actions and repeated sequences also increase in their automaticity and become represented at this level so that frequently repeated appraisal emotion sequences can eventually occur automatically and outside awareness. 3 . The propositional system: this system is the one beloved of cognitive therapy in which verballinguistic statements (propositions) are represented. 4. The schematic model system: this is the high-level system in which dynamic and ever-changing models of the self and the world are constructed and which provides overall executive control. In relation to emotion, effortful appraisal of events and situations leads to schematic models that generate emotions; appraisals typically evaluate events and situations in relation to key goals, both personal and interpersonal, with the appraisal outcomes generating different emotions [16]. In SPAARS, emotions are described as appraisal based on against an individual's goals and this makes the theory functional in nature. The theory proposes two routes for the generation of emotions, namely a direct one in which the appraisals have become automatized and the other where these are still not automatized. It provides a useful approach within which both basic and complex emotions can readily be understood. The theory can also be applied for explaining the disorders of emotion and it can be used to generate novel therapeutic interventions for them [19].

Considering the theoretical and research basis that we mentioned, the aim of this study is to survey the effectiveness of emotion-focused cognitive therapy in decreasing depression due to marital relationship problems.

\section{Hypothesis}

Emotion-focused cognitive therapy reduces the depression due to marital relationship problems in the experimental group as compared to the control group.

\section{Materials and Methods}

\subsection{Design}

This study is semi-experimental with pre-test, post-test and control group. The convenience sampling method was used in the present study.

\subsection{Participants}

Statistical population included all couples referred to the Ferdowsi University of Mashhad Clinic of Psychology in response to the call for research voluntarily participated in this study in the fall of 2015. These couples completed a three-stage screening process. At the baseline assessment, first the interview, which was focused on marital relationship problems and depression symptoms were conducted. It should be noted that this assessment was conducted on the basis of diagnostic criteria which was explained by Oleary and Daniel [20]. The criteria was as follows: feeling of deep sadness and dissatisfaction from life, difficulty in concentrating, lack of interest in sex, difficulty in sleeping, lack of energy, withdrawing from the social activities, low self-esteem, feelings of hopelessness, feelings of guilt. These feelings occur due to the communication problems, slow or fast motion and alternate crying. A lack of responsiveness to antidepressants. Convinced that the cause of depression is communication problems. Then the communication patterns questionnaire (CPQ) was given to them. In the next stage, couples who had two kinds of communication style, mutual avoidance or demand-withdraw, were asked to fill out a BDI.II questionnaire in order to diagnose the level of depression. The couples, who got a score of 14 or more in the BDI.II questionnaire, they were randomly divided into two groups: an experimental group (5 couples) and a control group (5 couples). Inclusion criteria to enter this study were: 1. lack psychotherapy; 2 . The absence of psychosis; 3 . A lack of medical conditions that could affect the marital relationship such as thyroid dysfunction, diabetes mellitus, multiple sclerosis, etc.; 4 . the presence of both (wife and husband) in the counseling sessions; 5 . With the education higher than high school diploma; 6 . Not having extra-marital relationships 6 . Not in the process of a divorce. 7. The absence of depression before marriage (participant has not sought to professional helping in terms of depression and they have not received clinical depression diagnosis before marriage).

The average lifespan of the experimental group was 27.60 and the control group was 30.50 . The mean scores of years that the couples have been together in the experimental group were 4.90 and in the control group was 5.60. In terms of education level, $10 \%$ of participants received a 12 th-grade education (high school diploma), 50\% had a bachelor degree, $30 \%$ had a Master's degree, $10 \%$ had Ph.D. respectively. 


\subsection{Measures}

\section{Communication Patterns Questionnaire (CPQ)}

The CPQ is a 35 -items self-report instrument designed to assess the extent to which couples employ various types of interaction strategies when dealing with the relationship problems. CPQ designed to assess couples behavior during three stages of conflict: 1 . when a problem in the relationship arises, 2. during their discussion of the relationship problem, and 3. after the discussion of the relationship problem. Each partner indicates what typically occurs in their relationship on a nine-point Likert scale ranging from "very unlike us" 1 to "very like us" 9. In this study the normality form of CPQ in Iran was used. It is comprised of four subscales: (a) the constructive communication subscale, (b) the female demand and male withdraw subscale, (c) the female withdraw and the male demand subscale and (d) the mutual avoidance subscale. Previous research using the CPQ has demonstrated satisfactory reliability and validity of the different scales. Cronbach's alphas varied between 0.50 to 0.87 [21; 22]. In Iran, Ebadatpour [23] in order to measure the validity of this questionnaire, reveals the correlation between the scales of this questionnaire with ENRICH Marital Satisfaction Scale. The correlation coefficient obtained for the constructive communication subscale, the mutual avoidance subscale and demand-withdraw patterns were $58 \%, 58 \%$ and $35 \%$, respectively. All of them were significant at 0.01 level Cronbach's alpha. She also reported the reliability of the subscales of this questionnaire by Cronbach's alpha method: (the constructive communication subscale $(0.70)$, the mutual avoidance subscale $(0.71)$, the female demand and male withdraw subscale (0.51) and the female withdraw and male demand subscale $(0.52)$.

\section{Beck Depression Inventory (BDI-II)}

Beck depression scale was designed by Beck in 1967 as a self-report questionnaire. Depression Inventory-II (BDI-II) is a 21-item self-report version of a questionnaire for depression in adults and adolescents over the age of 13 . Scores are based on four options (0-3). The questionnaire is a self-evaluation test and takes 5-10 minutes to finish. The scores range from 0 to 63 . The following scores can be used to indicate the overall level of depression: 0 to 13: no or minimal depression; 14 to 19: mild depression; 20 to 28 : moderate depression; 29 to 63: severe depression. [24]. the BDI-II is positively correlated with the Hamilton Depression
Rating Scale with a Pearson $r$ of 0.71 , showing good agreement. The test was also shown to have a high one-week test-retest reliability (Pearson $r=0.93$ ), suggesting that it was not overly sensitive to daily variations in mood [25]. The test also has high internal consistency $(\alpha=0.91)$ [26]. In Iran the validity of this test was 0.91 , the range of the correlation coefficients with the questionnaire were reported between 0.54 and 0.68 [24].

\subsection{Procedure}

The tests administered in therapy rooms of Ferdowsi University of Mashhad Clinic of Psychology. The experimental group received 10 session of emotion-focused cognitive therapy for 90 minutes every week. Whereas the control group by the end of the study received no treatment. In posttest both groups (The experimental group and the control group) at the end of therapy sessions filled out a questionnaire (BDI-II and CPQ). It should be noted after the end of study process the control group receives 10 session of emotion-focused cognitive therapy.

\subsection{Intervention}

Power suggests that the treatment has three phases: 1 . the alliance-assessment phase. 2. The work phase 3. The termination phase [16].

The summary of therapy session which it used in this study is presented in table 1 .

\subsection{Data Analysis}

The data gathered from implementing CPQ and BDI-II in pre-test and post-test is analyzed using descriptive statistics to show demographic properties. For inferring the data, covariance analysis (ANCOVA) is used to test the assumption and control the effect of pre-test. All stages of analyzing the data are done by SPSS- 21 .

\section{Results}

The mean and standard deviation of pre-test and post-test scores of CPQ (mutual avoidance and demand-withdraw) and BDI-II in the experimental and the control groups are presented in table 2 . 
Table 1. Summary of Emotion Focused Cognitive therapy sessions

\begin{tabular}{|c|c|}
\hline Session 1 & $\begin{array}{l}\text { Familiarity between therapist and couples, establishing the fine relationship and therapeutic alliance, description the rules of } \\
\text { therapy sessions. }\end{array}$ \\
\hline Session 2 & $\begin{array}{l}\text { Using various techniques in order to create a therapeutic alliance in this session, collecting appropriate range of standard } \\
\text { information such as Emotion Diary, Basic Emotions Scale (anger, sadness, disgust, anxiety, joy), Diary Record (thoughts). All of } \\
\text { these instruments, designed to assess in emotion-focused cognitive therapy especially. The purpose of this scale is to specify the } \\
\text { subject that how much or how often a person experiences certain emotion. }\end{array}$ \\
\hline Session 3 & $\begin{array}{l}\text { Checking of last session assignment, collecting the assessing information continued (Significant Others Scale and Clinical } \\
\text { Interview Form). Also this scale designed to assess in EFCT specially. At the end of the third session, the first stage of } \\
\text { Emotion-focused cognitive therapy, alliance-assessment phase, is finished. }\end{array}$ \\
\hline Session 4 & $\begin{array}{l}\text { Emotion assessments, clinical background and social network were used in order to determine the emotion problem for each } \\
\text { couple. }\end{array}$ \\
\hline Session 5 & $\begin{array}{l}\text { First, Emotion Diary and Diary Record (thoughts) examined. After that, cognitive techniques were taught to couples in order to } \\
\text { reduce the amount of time that clients pay attention to irrational thoughts. These techniques include distraction, sensory } \\
\text { awareness, memories and pleasant fantasies and mental workout. This technique was performed by focusing on the couples } \\
\text { problems. }\end{array}$ \\
\hline Session 6 & $\begin{array}{l}\text { Clients report the techniques learned and used in the last week. It is determined that each of the couples experienced too much } \\
\text { emotion or too little of the emotions. It is important to determine how to continue the treatment. Discussion was organized based } \\
\text { on the five basic emotions of fear, sadness, anger, disgust and happiness that accrued during the cycle of their interactive. }\end{array}$ \\
\hline Session 7 & $\begin{array}{l}\text { It was talked about labeling and documents with clients and also they were taught about the documentation techniques. Three } \\
\text { questions technique was administered to clients in order to help them have a proper interpretation of events that happening in their } \\
\text { marital relations. }\end{array}$ \\
\hline Session 8 & $\begin{array}{l}\text { At this meeting, according to different emotions of a clients at different times and about different situation in marital life, therapist } \\
\text { converse with the clients about how emotion is more balanced and they are asked to give their opinion and what kind of } \\
\text { reaction and interpretation do they have (apart from the previous reaction). The couples receive help in order to increase their } \\
\text { knowledge about emotions and the nature of emotions. In addition to this, therapist tried to consider and teach on how to accept a } \\
\text { thrilling experience and teaching alternative strategies for emotion regulation instead of using ineffective strategies such as drugs, } \\
\text { alcohol and behavioral avoidance. At the end of the eighth session, the second phase of Emotion-Focused Cognitive Therapy was } \\
\text { finished. }\end{array}$ \\
\hline Session 9 & $\begin{array}{l}\text { Providing information about culture, emotion, emotion tenderization and its consecuencias. Discussed about issues in relation to } \\
\text { the termination of treatment such as facilitation of the client's independent functioning, enhancement of the client's sense of } \\
\text { competence, reinforcement of the use of social support, positive reinforcement of the client's gain. }\end{array}$ \\
\hline Session 10 & $\begin{array}{l}\text { The couples are asked to compare his or her performance from the beginning of treatment up to this session. Therapist encourages } \\
\text { the couples because of the progress achieved in the treatment. Other issues are discussed in relation to termination of treatment } \\
\text { including acknowledgement of the couple's sense of loss, exploration of client's feeling about therapy termination, therapist's } \\
\text { self-disclosure of feeling about conclusion, mutual feedback about therapy and review, management of any post-therapy contacts } \\
\text { etc. }\end{array}$ \\
\hline
\end{tabular}

Table 2. Variables scores in the experimental and the control group

\begin{tabular}{|c|c|c|c|c|}
\hline variables & groups & Stages & mean & Standard deviation \\
\hline & & Pre-test & 35.40 & 1.67 \\
\hline & experimental & Post-test & 23.60 & 3.57 \\
\hline mutual avoidance & & & & 8.82 \\
\hline & & Pre-test & 23.60 & 8.60 \\
\hline & control & Post-test & 21.00 & 5.85 \\
\hline & & Pre-test & 33.40 & 6.50 \\
\hline demand-withdraw & experimental & Post-test & 20.40 & 3.04 \\
\hline & & & & 3.74 \\
\hline & control & Pre-test & 27.40 & 6.02 \\
\hline & & Post-test & 28.00 & 4.36 \\
\hline
\end{tabular}


As can be seen from table 2 general information description like mean scores and standard deviation presented in pretest and posttest divided is to the experimental group and the control group in mutual avoidance, demand-withdraw subscales and BDI-II.

Before presenting the results of analysis of univariate covariance to compare the experimental and the control groups in overall mutual avoidance, demand-withdraw and BDI-II scores, it should be noted that the results of Kolmogorov-Smirnov tests was not significant $(\mathrm{p}>0.05)$. The lack of significance in Kolmogorov-Smirnov tests indicates that the data is normal. The results of the Levene's tests was not significant (mutual avoidance: $\mathrm{F}_{(8,1)}=1.65, \mathrm{P}=$ 0.23; demand-withdraw: $\mathrm{F}_{(8,1)}=3.35, \mathrm{P}=0.10$; depression: $\left.\mathrm{F}_{(1,18)}=0.29, \mathrm{P}=0.59\right)$. Therefore the homogeneity of variance assumption was supported. Also the homogeneity of regression slopes assumption was observed; for relationships between variables and pre-test (mutual avoidance: $\mathrm{F}=1.02$. $\mathrm{P}=0.35$; demand-withdraw: $\mathrm{F}=0.73$. $\mathrm{P}=0.42$; depression: $\mathrm{F}=3.89$. $\mathrm{P}=0.06$ ).

As can be seen from table 3 , there is a significant difference in terms of mutual avoidance, demand-withdraw subscales and depression between the couples in the experimental group to compare the control group. In other words, there was a decrease in the level of mutual avoidance, demand-withdraw subscales and depression in the experimental group who received the emotion-focused cognitive therapy as compared to the control group who received no treatment (mutual avoidance: $\mathrm{F}=25.12, \mathrm{P}=0.002$; demand-withdraw: $\mathrm{F}=5.87, \mathrm{P}=0.04$; depression: $\mathrm{F}=60.04$, $\mathrm{P}=0.001$ ). The effect size is equal to $0.78,0.45$ and 0.77 for mutual avoidance, demand-withdraw subscales and depression, respectively. This demonstrates that $78 \%$ of the mutual avoidance, 0.45 of demand-withdraw and 0.77 of depression scores in the post-test is related to the effect of emotion-focused cognitive therapy.

\section{Discussion}

This study examined the effectiveness of EFCT in reducing depression due to marital relationship problems. As it can be seen from table 3, EFCT decreased mutual avoidance and demand-withdraw communication patterns. Moreover, the depression was decreased more in the experimental group as compared to the control group (see table 3).

In some studies such as by Suveg, Kendall, Camer and Robin [27], EFCT has been conducted for the treatment of mood disorders. In this current study, the authors examined the efficacy of an Emotion-focused Cognitive Therapy (ECBT) for six anxious youths. They used Emotion Expression Scale for Children (EESC) and Emotion Regulation Checklist (ERC). According to the results, ECBT caused improvement in anxious symptomatology, emotion understanding and regulation skills and overall functioning. In terms of variables, sampling, methodology and participants, this study is quite different from our study. But, as anxiety and depression are mood disorders, the study tend to be similar, in terms of efficacy of Emotion-Focused Cognitive-Behavioral therapy.

Table 3. the results of covariance analysis for comparison groups in mutual avoidance subscale, Demand-withdraw subscale and depression

\begin{tabular}{|c|c|c|c|c|c|c|c|}
\hline variables & source & Som of squares & $\mathrm{Df}$ & Mean square & $\mathrm{F}$ & $\mathrm{P}$ & $\begin{array}{c}\text { Partial Eta } \\
\text { squared }\end{array}$ \\
\hline & Pre-test & 319.20 & 1 & 319.20 & 79.82 & 0.001 & 0.91 \\
\hline \multirow[t]{4}{*}{$\begin{array}{l}\text { Mutual avoidance } \\
\text { (post-test) }\end{array}$} & groups & 100.45 & 1 & 100.45 & 25.12 & 0.002 & 0.78 \\
\hline & Error & 27.99 & 7 & 3.99 & & & \\
\hline & Total & 5337 & 10 & & & & \\
\hline & Pre-test & 28.25 & 1 & 28.25 & 1.00 & 0.35 & 0.12 \\
\hline \multirow[t]{4}{*}{$\begin{array}{l}\text { Demand-withdraw } \\
\text { (post-test) }\end{array}$} & groups & 165.40 & 1 & 165.40 & 5.87 & 0.04 & 0.45 \\
\hline & Error & 196.94 & 7 & 28.9913 & & & \\
\hline & Total & 6226 & 10 & & & & \\
\hline & Pre-test & 121.06 & 1 & 121.06 & 6.60 & 0.02 & 0.28 \\
\hline \multirow[t]{3}{*}{$\begin{array}{c}\text { Depression } \\
\text { (post-test) }\end{array}$} & groups & 1099.97 & 1 & 1099.97 & 60.04 & 0.001 & 0.77 \\
\hline & Error & 311.44 & 17 & 18.32 & & & \\
\hline & Total & 7799 & 20 & & & & \\
\hline
\end{tabular}


Afshari, Neshat-doost, Maracy, Ahmadi and Amiri [28] compare emotion-focused cognitive behavioral group therapy and cognitive behavioral group therapy in children with separation anxiety disorder. The results showed that ECBT as compared to CBT effectively improve the emotion regulation strategies in children with separation anxiety. Therefore, these studies supported the efficacy of Emotion-Focused Cognitive Therapy on mood disorders. Furthermore, in the literature review for the treatment of depression in couples, the similar treatment of emotion-focused cognitive therapy such as emotion-focused therapy is mentioned. Dessaulles and Johnson [29] examined the effectiveness of Emotion-Focused Therapy for Couples in the Treatment of Depression. In this study, Emotion-Focused Therapy for couples was compared to pharmacotherapy in the treatment of a major depressive disorder. Results indicated that both interventions were equally effective in symptom reduction. In another study by Dalgleish, Johnson, Burgess Moser, Lafontaine, Wiebe and Tasca [30], the relationship satisfaction and attachment trajectories in the couples was investigated. Their finding supports the theoretical assumption that EFT helps the couples engaged in therapy by creating lasting relationship satisfaction and attachment change. Soltani, Molazadeh, Mahmoodi and Hosseini [31] studied the effectiveness of Emotion Focused Couple Therapy on Intimacy of Couples. At least, authors concluded that EFCT increased intimacy in the experimental group as compared to the control group. Goldman, Greenberg and Angus [32] examined the effects of adding emotion-focused interventions to the client-centered relationship conditions in the treatment of depression. Their results showed that adding emotion-focused intervention is a useful intervention in order to enhance the treatment for depression of couples. These studies are supported from the efficacy of emotional interventions in the treatment of depression among the distressed couple. Therefore, they are consistent with the results of our study.

Generally, a number of factors led to the success of Emotion-Focused Cognitive Therapy in this study. Firstly, in addition to depression, one of the inclusion criteria to enter in this study was marital relationship problems. All the participants were evaluated on the basis of the criteria of depression due to marital relationship problems [20].On the other hand; the improvement in their marital relationship problems could reduce the severity of their depression. Since, the main focus of couple's therapy (regardless of the approach) is on the marital relationship; therefore, couple therapy is potentially an appropriate treatment for the depression [33]. In the systematic perspective, marital relationship problems and disease symptoms that occur in every wife and husband are the result of a rotational relationship [34]. Emanuels-Zuurveen and Emmelkamp [35] and Foley, Rounsaville, Wessman, Sholomaskas and Chevron [36] used spouse cooperation for the treatment of depression. In both of the studies, group therapy became a source of reducing the depression and equally improving the martial performance as reported in the case of a group where the spouse cooperates in the treatment process. Secondly, the findings of this study are coordinated with the assumptions of emotion-focused cognitive therapy because the emotional beliefs, as well as rational beliefs, are considered in this model. In contrast to CBT, Power and Dalgleish, it is believed that the relationship between cognition and emotion is not linear. In Beck's cognitive theory, it is believed that the changes in rational beliefs lead to the changes in emotions (general processing), whereas, in the new cognitive theories such as emotion-focused-cognitive theory, it is believed that the cognitive-emotional model includes a wide variety of processing systems and representations (schematic, propositional, analogical and associative representational systems) processing is parallel in these systems. In other words, when the treatment takes place, it affects the whole system (both rational and emotional beliefs). In addition to that, all the components of this system could be placed in a special status until the rational and emotional beliefs were changed. In fact, this matter leads to improvement in the client's conditions [16]. In fact, both the cognitive and emotional aspects were applied in a couple relationships through this treatment in order to reduce depression. Thirdly, in this therapy model, utilizing and challenging the different kinds of techniques such as sensory awareness techniques, reviews of emotions, checking negative automatic thoughts and basic emotions are the best processes. Working on the rational and emotional beliefs simultaneously leads to changing emotional responses. In this model, working on the physical effects, emotions, thoughts and feelings of a person simultaneously lead to pleasant change of depression symptoms which includes both mental and physical dimensions. But, in the therapeutic model of Beck (CBT), the treatment is done only at the level of rational beliefs and afterwards, it is perceived that the emotion is modified, whereas, most of the time, the emotional judgment is independent of the cognition judgment. For this reason, sometimes the depressed patients who are merely treated by CBT may have a relapse [16].

Fourthly, the individuals express their emotions by the communication patterns $[37 ; 38]$. During the therapy session, the process of revealing and working on the emotion problems and focus on couples help the individuals to use the more constructive communication patterns as compared to the past. By using the constructive communication patterns as well as the implementation of techniques for the reduction of depression during the therapy sessions, the depression was reduced more in the couples of experimental group as compared to the control group.

Fifthly, it is a fact that the emotional effects create an impact on the interactions amongst people. In other words, the emotional effects of a person may result in the selective behavioral reaction by the other person.

When the depressed couples express their main emotions 
such as fear and anger, instead of isolation, avoiding each other and objection, they are actually aware of the original meaning of their behavior. As a result of this, they can understand that all these efforts are made in order to save their relationship only [39]. Due to the fact that both cognitive and emotional factors are taken into consideration by EFCT, the Emotion-focused cognitive therapy can be a suitable treatment for solving the depression among couples. Thus, the use of this therapy is recommended to therapists.

\section{Conclusions}

In this study, we examined the effectiveness of Emotion-Focused Cognitive Therapy on marital relationship problems. The results showed that this therapy is a useful intervention for supporting the couples who suffer from depression due to marital relationship problems. In fact, the use of cognitive and emotional techniques and benefits of couple therapy were the important factors which led to success in this clinical trial.

\section{REFERENCES}

[1] Trenholm, S. \& Jensen. A. Interpersonal communication. Oxford university press, USA; 1996.

[2] Tavakolizadeh, J., Nejatian, M., \& Soori, A. The Effectiveness of communication skills training on marital conflicts and its different aspects in women. Procedia-Social and Behavioral Sciences. 2015; 171, 214-221.

doi:10.1016/j.sbspro.2015.01.112.

[3] Gottman, J. M., \& Notarius, C. I. Marital research in the 20th century and a research agenda for the 21 st century. Family process. $2002 ; 41(2), 159-197$. doi:10.1111/j.1545-5300.2002.41203.x.

[4] Parr, P., Boyle, R. A., \& Tejada, L. I said, you said: A communication exercise for couples. Contemporary Family Therapy. 2008; 30(3), 167-173. doi:10.1007/s10591-008-9062-6.

[5] Carroll, J. S. Couple communication as a mediator between work-family conflict and marital satisfaction. thesis for master degree. school of family life. Brigham University. Poro Utah. United States. 2012.

[6] Whisman, M. A. The association between depression and marital dissatisfaction. In S.R.H. Beach (ed), Marital and family processes in depression: A scientific foundation for clinical practice. (pp. 3-24), Washington, DC: American Psychological Association. 2001

[7] Dessaulles, A., Johnson, S.M., \& Denton, W. Emotion-focused therapy for couples in the treatment of depression: A pilot study. The aAmerican Journal of Family tTherapy. 2003; 31(5). 345-353. doi: $10.1080 / 01926180390232266$.

[8] Kronmuller, K. T., Backenstrass, M., Victor, D., Postelnicu, I.,
Schenkenbach, C., Joest, K., Fiedler, P., Mundt, C. Quality of marital relationship and depression: result of a 10-year prospective follow-up study. Journal of Affective iDsorder. 2011; 128, 64-71. doi: 10.1016/j.jad.2010.06.026.

[9] Joiner, T. E., Brown, J. S., \& Kistner, J. The interpersonal, cognitive, and social nature of depression. Mahwah, NJ: Erlbaum; 2006.

[10] Hammen, C., \& Brennan, P. A. Depressed adolescents of depressed and nondepressrd mothers: Test of an interpersonal impairment hypothesis. Journal of Consulting and Clinical Psychology, 2001; 69, 284-249. doi:10.1037/0022-006X.69.2.284.

[11] Beach, S. R. H., Kim, S., Cercone-Keeney, J., Gupta, M., Arias, I., \& Brody, G. Physical aggression and depressive symptoms: Gender Asymmetry in Effects? Journal of Social and Personal Relationships, 2004; 21, 341-360. doi: 10.1177/0265407504042836.

[12] Gurman, A. S. Clinical handbook of couple therapy $\left(4^{\text {th }} \mathrm{ed}\right)$. New york: guilford press; 2008.

[13] World Health Organization. Depression. http://www.who.int/mediacentre/factsheets/fs369/en/ Accessed 16.4; 2016.

[14] Nyer, M. B., Fisher, L. B., Farabaugh, A. The Massachusetts general hospital handbook of cognitive behavioral therapy. Springer New York; 2016.

[15] Butler, A. C., Chapman, J. E., Forman, E. M., Beck, A. T. The empirical status of cognitive-behavioral therapy: A review of meta-analyses. Journal of Clinical Psychology Review. 2006; (26) 17-31. doi: 10.1016/j.cpr.2005.07.003.

[16] Power, M. Emotion-focused cognitive therapy. Willey-blackwell (A John Wiley \& Sons, Ltd., publication; 2010.

[17] Power, M.j., \& Dalgleish, T. Cognition and Emotion: From Order to Disorder ( ${ }^{\text {nd }}$ edn). Hove: Erlbaum; 2008.

[18] Diener, C., Kuehner, C., Wencke, B., Ubi, B., Wessa, M., Flor, H. A meta-analysis of neurofunctional imaging studies of emotion and cognition in major depression. Journal of Nouroimage. 2012; 61, 677-685. doi:10.1016/j.neuroimage.2012.04.005.

[19] Khetrapal, N. SPAARS Approach: Integrated cognitive model of emotion of Attention Deficit/Hyperactivity Disorder. Europe's Journal of Psychology, 2007; 3(3). doi: 10.1016/S1353-8020(09)70147-6.

[20] O'leary, Heyman, R, Jongsma, AE. (2014). The couples Psychotherapy Treatment Planner, $2^{\text {nd }}$ Edition. Wiley. Hoboken

[21] Christensen, A. A., \& Heavey, C. L. Gender and social structure in the demand/withdraw pattern of marital conflict. Journal of Personality and Social Psychology, 1990; 59, 73-81. doi: 10.1037/0022-3514.59.1.73.

[22] Heavey, C. L., Layne, C., \& Christensen , A. Gender and conflict structure in marital interaction: A replication and extension. Journal of Consulting and Clinical Psychology. 1993; 61, 16-27. doi: 10.1037/0022-006X.61.1.16.

[23] Ebadatpour, B. The normalization of the Communication Patterns Questionnaire in Tehran city in 2000-2001. thesis for 
master degree (MA). Tarbiatmoallem University. Tehran; 2000.

[24] Dobson, K.S., Mohammadkhani, P. Psychometric characteristics of Beck Depression Inventory in a large sample of patients with major depressive disorder. Prevention of Diseases and Mental Disorders, 2007; 29(8), 80-6. doi: 10.1590/1516-4446-2012-1048.

[25] Beck, A. T., Steer, R. A., \& Brown G.K. Manual for the Beck Depression Inventory-II. San Antonio, TX: Psychological Corporation; 1996.

[26] Beck, A. T., Steer, R. A., Ball, R., Ranieri, W. Comparision of Beck Depression Inventories-IA and -II in psychiatric outpatients. Journal of Personality Assessment. 1996; 67 (3): 588-597. doi: 10.1207/s15327752jpa6703_13.

[27] Suveg, C., Kendall, P. C., Comer, J. S., Robin, J. Emotion-focused cognitive-behavioral therapy for anxious youth: a multiple-baseline evaluation. Journal Contemp Psychother 2006; 36. 77-85. doi: 10.1007/s10879-006-9010-4.

[28] Afshari, A., Neshat-Doost, H. T., Maracy, M.R., Ahmadi, M. K., Amiri, S. The effective comparison between emotion-focused cognitive behavioral group therapy and cognitive behavioral group therapy in children with separation anxiety disorder. Journal of Research in Medical Sciences. 2014; 19(3). 221-227. doi:

[29] Dessaulles, A., Johnson, S. M., \& Denton, W. H. (2003). Emotion-focused therapy for couples in the treatment of depression: A pilot study. The American Journal of Family Therapy, 31(5), 345-353.doi:10.1080/01926180390232266.

[30] Dalgleish, T. L., Johnson, S. M., Burgess Moser, M., Lafontaine, M. F., Wiebe, S. A., \& Tasca, G. A. (2015). Predicting change in marital satisfaction throughout Emotionally Focused Couple Therapy. Journal of Marital and Family Therapy, 41(3), 276-291.
[31] Soltani, A., Molazadeh, J., Mahmoodi, M., \& Hosseini, S. (2013). A study on the effectiveness of emotional focused couple therapy on intimacy of couples. Procedia-Social and Behavioral Sciences, 82, 461-465. Doi:10.1016/j.sbspro.2013 .06.293.

[32] Goldman, R. N., Greenberg, L. S., \& Angus, L. (2006). The effects of adding emotion-focused interventions to the client-centered relationship conditions in the treatment of depression. Psychotherapy Research, 16(5), 537-549. Doi: $10.1080 / 10503300600589456$.

[33] Whisman, M. A., \& Beach, S. R. (2012). Couple therapy for depression. Journal of clinical psychology, 68(5), 526-535.

[34] Goldenberg, H., \& Goldenberg, I. (2012). Family therapy: An overview. Cengage Learning.

[35] Emanuels-Zuurveen, L., \& Emmelkamp, P. M. G. Individual behavioural cognitive therapy vs. Marital therapy for depression in martially ditressed couples. British Journal of Psychiatry, 1996; 196, 181-188.

[36] Foley, S., Rounsaville, B. J., Wessman, M. M., Sholomaskas, D., \& Chevron, E. Individual versus conjoint interpersonal therapy for depressed patients with marital disputes. International Journal of Family Psychiatry, 1989; 10, 29-42.

[37] Wuerker, A. M. (1996). Communication patterns and expressed emotion in families of persons with mental disorders. Schizophrenia bulletin, 22(4), 671.

[38] Adams, K., Cimino, J. E., Arnold, R. M., \& Anderson, W. G. (2012). Why should I talk about emotion? Communication patterns associated with physician discussion of patient expressions of negative emotion in hospital admission encounters. Patient education and counseling, 89(1), 44-50.

[39] Harper, J. M., and Sandbrg J. G. (2009). Depression and communication processes in later life marriage. Aging \& mental Health Journal, 13, 564-556. 